\title{
An Assessment of Urban Heat Island in Akure Using Geospatial Techniques
}

\author{
${ }^{1}$ Aderoju Olaide .M, ${ }^{2}$ Samakinwa E Kayode, ${ }^{3}$ Ibrahim dris \\ ${ }^{I}$ Department of Strategic Space Applications,National Space Research and Development Agency Abuja. \\ ${ }^{2}$ Department of Meteorology, Federal University of Technology Akure, Ondo State, Nigeria. \\ ${ }^{3}$ Department of Strategic Space Applications, National Space Research and Development Agency Abuja
}

\begin{abstract}
Urban Heat Island is a phenomenon in which the temperature of an urban area is several degrees higher than its immediate sub-urban area. This paper was aimed at using satellite Remote Sensing and Geographic Information system (GIS) to investigate the urban heat Island in Akure. The study employed the Radiative Transfer Method in estimating Land Surface Temperature (LST) using Landsat ETM+ acquired on the $3^{\text {rd }}$ January, 2002 with a spatial resolution of $30 \mathrm{~m}$ which is sufficient for measurement of some important environmental parameters. The result of this study showed that the effect of Urban Heat Island (UHI) is not always at the center of the city but sometime in the outskirt where a lot of developmental activities were going on toward the direction of expansion of Akure. It was shown that the most extensive Urban Heat Island (UHI) was distributed in the central part of the Central Business District, comprising of the popular market (OjaOba), high court road and Alagbaka government area.
\end{abstract}

Key Words; Urban Heat Island (UHI), Remote sensing (RS), Geographic Information Systems (GIS), Land Surface Temperature (LST), Normalize Differential Vegetative Index (NDVI), Land Use (LU), Land Cover (LC).

\subsection{Background to the study}

\section{Introduction}

Urbanization is the conversion of land to uses associated with growth of populations and economy. This is a main type of land use and land cover change in human history and it has a great impact on climate. By covering with buildings, roads and other impervious surfaces, urban areas generally have higher solar radiation absorption, and a greater thermal capacity and conductivity such that heat is stored during the day and released by night. Therefore, urban areas tend to experience a relatively higher temperature compared with the surrounding rural areas. This thermal difference in conjunction with waste heat released from urban houses, transportation and industry contribute to the development of Urban Heat Island (UHI). Urban Heat Island develops when a large fraction of the natural land-cover in an area are replaced by built surfaces that trap incoming solar radiation during the day and then re-radiate it at night. The rapid growth in human population and economic output per capital has been an unprecedented features of this industrial era (Cohen, 1995 and Sieferie, 2001), impacting great consequences on the global environment over the past century (Rosa et al, 2004). The temperature difference between the urban and the rural areas are rising to several degrees with special urban, topographical and meteorological conditions (Mather 1986).

Brightness temperature information from satellite data together with simultaneous satellite land use/ cover data is very useful to understand surface conditions of urban areas. It is possible to evaluate the relationship between the ground cover situation and city temperature using satellite data. It has now become possible to obtain detailed knowledge of the land cover that determines the high-temperature of an urban area by utilizing information from a wide area.

The brightness temperature observed by satellite images is very useful for assessing area-wide temperatures distributions for the study of thermal environmental problems of urban areas. Studies on surface temperature characteristics of urban areas using satellite remote sensing data have been conducted primarily using NOAA AVHRR data (Balling and Brazell 1988, Roth et al. 1989, Gallo et al. 1993a). The spatial resolution of NOAA $(1.1 \mathrm{~km})$ data is found suitable only for small-scale urban temperature mapping. The much higher resolution $(120 \mathrm{~m})$ Landsat TM and $(60 \mathrm{~m})$ Landsat ETM+ thermal infrared data were seldom used to derive surface temperature.

Land use affects land cover and changes in land cover affect land use. A change in either however is not necessarily the product of the other. Changes in land cover by land use do not necessarily imply degradation of the land. However, many shifting land use patterns driven by a variety of social causes, result in land cover changes that affects biodiversity, water and radiation budgets, trace gas emissions and other processes that come together to affect climate and biosphere (Meyer, Turner, 1994 and Zubair, 2006). Urbanization can have significant effects on local weather and climate (Landsberg 1981). Of these effects one of the most familiar is the urban heat island, for which the temperatures of the central urban locations are several degrees higher than 
those of nearby rural areas (Streutker, 2002). In Akure, land use/cover patterns have undergone a fundamental change due to accelerated expansion since 1976. Since then, urban growth has been accelerated and has caused extreme stress to the environment. Also, the lack of appropriate land use planning and the measures for sustainable development, random urban growth has been creating severe environmental consequences.

Thus, there also is a need to assess the environmental impact of the rapid urban expansion therefore has lead to massive agricultural land disappearing in the city every year.

The integration of remote sensing and geographic information systems (GIS) has been widely applied and been recognized as a powerful and effective tool in detecting urban land use and land cover change. Satellite remote sensing collects multi-spectral, multi-resolution and multi-temporal data, and turns them into information valuable for understanding and monitoring urban land processes and for building urban land cover datasets. GIS technology provides a flexible environment for entering, analyzing and displaying digital data from various sources necessary for urban feature identification, change detection and database development.

In this study, the relationship between land cover and temperature in an urban area was analyzed and examined using satellite data from Landsat ETM+ Band 6 of Landsat was used for brightness temperature which intersected with land use/ cover and NDVI from other bands of Landsat ETM+.

\subsection{Statement of Problem}

The city of Akure has seen remarkable growth in its urbanization in recent years, and its population during the past few decades has more than doubled from 239,124 in 1991 to 484,798 in 2006(Balogun et al, 2009).

Urbanization has been the major cause of climate modification and it results in surface temperature difference between urban and sub-urban areas. Urbanization brings about the removal of natural surfaces and replacing them with man-made materials such as buildings, roads (Asphalt) which have high thermal properties. The thermal properties of built-up land surfaces, soil and impervious surface result in more solar energy being stored and converted to sensible heat, and the removal of shrubs and trees reduces the natural cooling effects of shading and evapotranspiration (Pickett et al, 2001). Urban topography, surface roughness, morphology of buildings and anthropogenic activities contribute by reducing outgoing long wave radiation, hinder sensible heat loss, hinder distribution of heat and generate heat respectively (Oke, 1982, Bonan, 2002 and Ifatimehin, 2007). All these alter the surface energy balance with a consequent increase in land surface temperature [average ambient temperature in urban systems is generally 2-3 degrees higher than the surrounding nonurban environment (Pickett, 1997)] in the urban environment. This then leads to the increase in sensible heat flux at the expense of latent heat flux, thereby forcing the development of meteorological events such as increased precipitation, which poses threat to the environment and the human population (Zhao and Wang, 2002). It exacerbate urban air pollution alter rainfall pattern in and around urban centers, and change the composition of biodiversity (Nowak et al, 2002) However, it also contributes to global warming (Changnon, 1992).

However, studies on the urban microclimate of tropical regions are scarce, the few that are also available in Nigeria have used mean monthly climatologically data or 2-3 hourly interval short term manual measurements (Balogun et al. 2009).

Until recently, the in situ measurements of air temperatures were conducted in the various studies of Urban Heat Island effects. This approach has major limiting factors in the quantitative description of the areal extent and in ascertaining the exact distribution of the variation in micro climates in Nigeria (Adebayo and Zemba, 2003). However, remote sensing technology with its earth monitoring sensors has made it possible to study the effects of urban heat island remotely on both local and global scales.

Also, monitoring the effect of UHI using In-situ measurement usually involves a huge amount of money.

1.3.1. Aim

\section{Aim and Objectives}

The aim of this study is to determine the spatial extent of the Heat Island in Akure.

\subsubsection{Objectives}

The specific objectives of this study are;

- $\quad$ To identify the land use/land cover of Akure;

- $\quad$ To find out the temperature variations associated with different land use/land cover types;

- To determine the spatial extent of urban heat Island in Akure.

\subsection{Justification of the Study}

Attempts have been made to investigate the effect of urban heat island on Akure but using in situ air temperature measurements. These in situ measurements make use of instruments which are very expensive to 
acquire but remotely sensed images with its areal coverage is cost effective and can provide a spatio-temporal resolution of the Urban Heat Island in an Area.

In recent times, the dynamics of Urban Heat Island requires a more powerful and sophisticated system such as Remote Sensed data and Geographic Information System which provides a general extensive synoptic coverage of the study areas and the estimation of emissivity, NDVI and surface temperature of the different land use land cover of the area.

\subsection{The Study Area}

The study area is Akure, the administrative capital of Ondo State. Akure became the state capital of Ondo State in 1976. Akure is the major dominating town of Akure South Local Government. It lies between longitude $5^{\circ} 06^{\prime} \mathrm{E}$ to $5^{\circ} 38^{\prime} \mathrm{E}$ (i.e., 727500 to 755000 Easting) and between latitude $7^{\circ} 07^{\prime} \mathrm{N}$ to $7^{\circ} 37^{\prime} \mathrm{N}$ (i.e., 790000 and 815000 Northing) in the Southwestern Nigeria. It is bounded by Akure North and Ifedore Local Government Areas in the north, Ile-Oluji/Oke-Igbo Local Government Area in the west, Owo Local Government Area in the east, and Idanre Local Government Area in the south. Akure experiences warm humid tropical climate, with average rainfall of about $1500 \mathrm{~mm}$ per annum with the little dry season in August and Annual average temperatures range between 21.4 and $31.1^{\circ} \mathrm{C}$, and its mean annual relative humidity is about 77.1\% (based on 1980-2007 data from the Nigerian Meteorological Agency).

Akure lies on a relatively flat plain of about $250 \mathrm{~m}$ above sea level within the Western Nigerian plains. The area towards Ado-Ekiti and Idanre are hilly and studded with large granite formation, rising to $410 \mathrm{~m}$ and $496 \mathrm{~m}$ above sea level respectively. These granitic formations are said to be of volcanic origin, underlained by basement complex rocks, which are mostly impermeable gneisses and granites.

The temperature is relatively high throughout the year. The mean monthly temperature of the town for the period of $2000-2007$ varies between $22^{\circ} \mathrm{C}$ and $31^{\circ} \mathrm{C}$ during harmattan (December-February) and $32^{\circ} \mathrm{C}$ in March.

Akure is one of the fastest growing urban centers in Nigeria. Her rate of population growth is much higher than for other cities in the country. The city had a population of less than 50,000 in 1952 and 70,641 in 1963 and was estimated as around 110,000 in 1980, the population increased to 157, 947 in and also increased to 484,798 in 2006. The people of Akure are of the Yoruba ethnic group.

The landscape of the region (Akure) is relatively flat, this means it is located on a plain and is crested by a popular river called river Ala.

The vegetation is tropical rainforest and drained by River Ala and its tributaries (Barbour et al., 1982; Iloeje, 1977; Uluocha and Ekop, 2002). Akure is the trade center for a farming region where cocoa, yams, cassava, corn and tobacco are grown. Cotton is also grown and used to weave cloth.

Akure is a city with various and liberal religious leanings. Christianity, Islam and Traditional worship forming the basis of faith for most residents. The preponderance of churches in the city cannot be ignored. There is the Central Mosque located at the heart of the city, forming a major landmark in the city. Worthy of mention is the fact that they all enjoy a peaceful co-existence in the city hub.

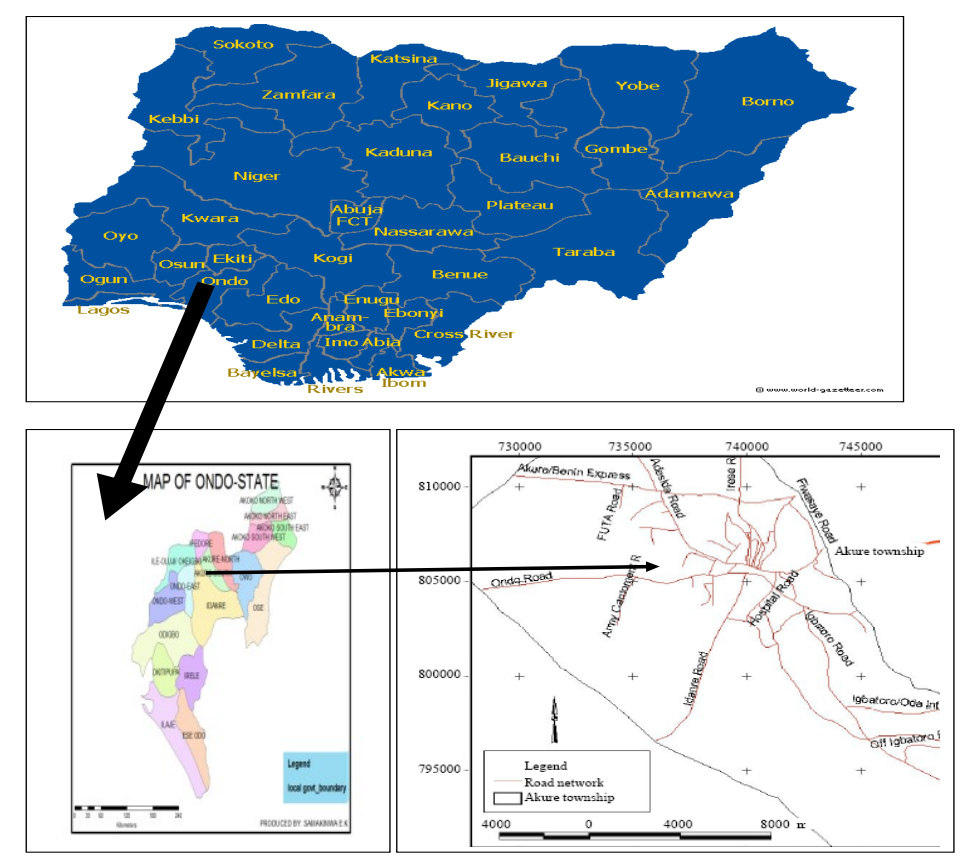

Fig 1.0 Maps showing Akure 


\subsection{DEFINITION OF TERMS}

Remote sensing (RS): is defined as any process whereby information is gathered about an object, area or phenomenon without being in contact with it. Given this rather general definition, the term has come to be associated more specifically with the gauging of interactions between earth surface materials and electromagnetic energy.

Geographic Information systems (GIS) are computerized systems for the storage, retrieval, manipulation, analysis, and display of geographically referenced data.

In Situ: is defined as a process of measuring the properties of air that comes in contact with an instrument.

Urban Heat Island (UHI): is a phenomenon of higher atmospheric and surface temperature occurring in urban areas than in surrounding rural area due to urbanization.

Land use (LU): This is the manner in which human beings employ the land and its resources.

Land cover (LC): Implies the physical or natural state of the Earth's surface.

Normalized Difference Vegetation Index (NDVI): refers to the difference ratio between land surface reflectance in the Near-infra red and Visible (Red) band.

\section{Methodology}

\subsection{DATA}

The digital data used in this study were collected by Landsat ETM + on $3^{\text {rd }}$ of January 2002 with $30 \mathrm{~m}$ spatial resolution. The spectral characteristics are shown in Table 1 below.

Table 3.1:Landsat ETM 2002, spectral consideration and source.

\begin{tabular}{|c|c|c|c|c||}
\hline BAND NO & WAVELENGTH(m) & $\begin{array}{c}\text { SPECTRAL } \\
\text { REGION }\end{array}$ & $\begin{array}{c}\text { SPATIAL } \\
\text { RESOLUTION(m) }\end{array}$ & SOURCE \\
\hline 2 & $0.52-0.60$ & Green & 30 & GLCF \\
\hline 3 & $0.63-0.69$ & Red & 30 & GLCF \\
\hline 4 & $0.76-0.90$ & Near infra-red & 30 & GLCF \\
\hline 6 & $10.4-12.5$ & $\begin{array}{c}\text { Thermal infra- } \\
\text { red }\end{array}$ & 60 & GLCF \\
\hline
\end{tabular}

Basically 5 software were used for this study viz,

- $\quad$ ILWIS 3.3: ILWIS is an acronym for the Integrated Land and Water Information System. It is a Geographic Information System (GIS) with Image Processing capabilities. ILWIS has been developed by the International Institute for Aerospace Survey and Earth Sciences (ITC), Enschede, The Netherlands. This was used for Radiometric Enhancement, development of land use land cover classes using Maximum Likelihood Classification and also used to produce NDVI map following a predefined algorithm given by the software.

Radiometric Enhancement was carried out using Histogram Equalization which redistributes pixel values with a nonlinear contrast stretch so that there are approximately the same numbers of pixel with each value within a range.

Classification using Maximum Likelihood decision rule is based on the probability that a pixel belongs to a particular class. The basic equation assumes that these probabilities are equal for all classes, and that the input bands have normal distributions.

- $\quad$ ARCGIS 9.3: was used in producing National, State and Local government boundary map of the study area and also in producing a Land Surface Temperature Map (Chloropleth).

ArcGIS is a vector based software designed by ESRI. It provides a scalable framework for implementing GIS (Geographic Information System) for its users. ArcGIS is an integrated family of GIS software products for building a complete GIS. More specifically, ArcMap and ArcCatalog were used for this project.

MICROSOFT EXCEL 2010: was used in calculating Spectral Radiance, Satellite Brightness Temperature, Emissivity and ultimately Land Surface Temperature.

Mathematical formulas used for the calculation of Spectral Radiance, Satellite Brightness Temperature and Land Surface Temperature were manually computed in the software using the Equal $(=)$ sign command. Microsoft Excel 2010, an electronic spreadsheet designed by Daniel S. Bricklin is a component of Microsoft office software 2010 and was produced by Microsoft Computer international.

- $\quad$ MICROSOFT WORD 2010: was used basically for the presentation of the research.

Microsoft word 2010 is also component of Microsoft office 2010 software and was produced by Microsoft Computer international. 


\subsection{METHODOLOGY}

This study will explore the conceptual and methodological issues of normalized land surface temperature as shown in the figure below;

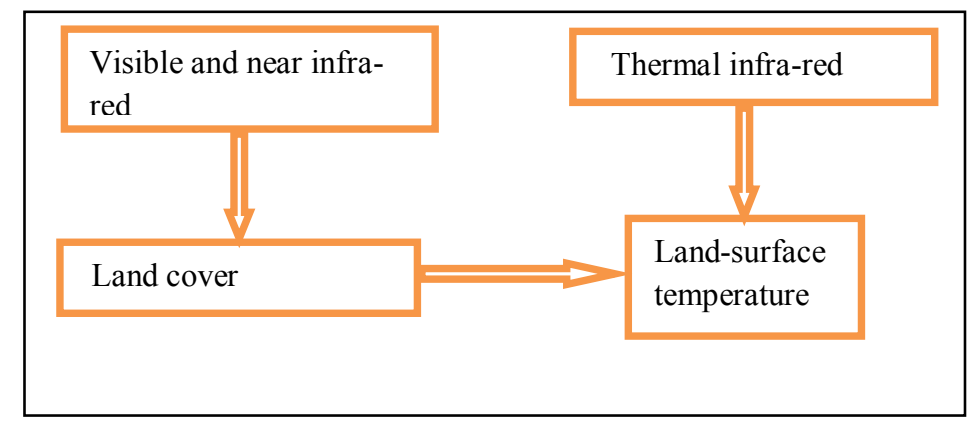

Figure 3.1: Data processing flow

Figure 3.1 shows the data processing flow in the study. The first step in the analysis was to make the Land use/cover classification using the ILWIS (3.3). In the study, supervised classification was employed to categorize the imagery. The classification result was used to provide the emissivity of the land use/cover categories. Emissivity was then used to estimate the land surface temperature from brightness temperature value in the thermal band.

\subsubsection{METHOD OF LAND USE/COVER CLASSIFICATION}

With the aid of ILWIS 3.3 software, the bands 2, 3 and 4 of the Landsat ETM+ image was enhanced using histogram equalization, rectified to a common UTM coordinate system (WGS84), and then radiometrically corrected. The imageries were then classified using three bands of green (2), red (3) and nearinfrared (4). The imageries were classified into 4 features namely:

$$
\begin{aligned}
& >\quad \text { Built-up } \\
& >\quad \text { Bare-Surface } \\
& \text { In this study, }
\end{aligned}
$$

* Built Up represents Residential areas, Industrial areas and any other surface developed.

* Bare Surface represents undeveloped lands, Roads, Rock outcrops and any other radiating surfaces.

- Vegetation includes cropland, forests and grasses.

* Water Body includes lakes, dams, rivers etc.

\subsubsection{METHODS OF DERIVING LAND SURFACE TEMPERATURE (LST)}

The main approaches to estimate LST are

a. $\quad$ To first separate the effect of intervening atmosphere and then decouple LST and LSE

b. To simultaneously remove atmospheric and emissivity effects

Hence, the prevalent methods of LST estimation require PRIORI surface emissivity information. There are 3 distinct LST estimation methods namely:

- $\quad$ Single-Channel method;

- $\quad$ Mono Window Algorithm; and

- $\quad$ Radiative Transfer method.

In this study, the Radiative Transfer Method will be used.

\section{* Radiative Transfer Method}




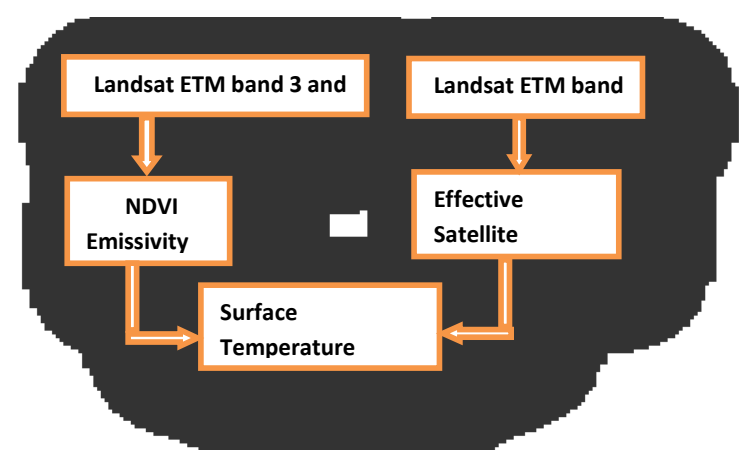

Figure 3.2: flowchart of estimating surface temperature using RTM adopted from Wuber, 2003.

The radiometrically corrected Landsat ETM+ band 3, 4 and the thermal infra-red (TIR) data (band6) will be used for this purpose. The following method will be adopted sequentially.

$>\quad$ Step 1: extraction of digital number(DN) from the TIR image;

$>\quad$ Step 2: conversion of DN to spectral radiance using

$$
\mathrm{L} \lambda=0.0370588 \times \mathrm{DN}+3.2
$$

Where $\mathrm{L} \lambda$ is the spectral radiance, $0.0370588=$ Gain and $3.2=\mathrm{Bias}$

The gain is the gradient of the satellite's pre-launch radiance and the Bias is the spectral radiance at DN equal zero. Conversion to spectral radiance is necessary to correct atmospheric effect on the reflectance value; absorption and scattering create an overall effect of "haziness" which reduces the contrast in the image. Scattering also creates the "adjacency effect" in which the radiance recorded for a given pixel partly incorporates the scattered radiance from neighbouring pixels. In order to make a meaningful measure of radiance at the Earth's surface, the atmospheric interferences must be removed from the data. This process is called "atmospheric correction".

$>\quad$ Step 3: calculate the effective satellite Temperature using

$$
\mathrm{TEs}_{\mathrm{N}}=\left(\mathrm{K}_{2}\right) / \mathrm{In}\left\{\left(\mathrm{K}_{1} / \mathrm{L} \lambda\right)+1\right\}
$$

Where $\mathrm{K} 2$ and $\mathrm{K} 1$ are the calibration constants and the values are

$\begin{array}{lrrr} & \text { Landsat TM } & \text { Landsat ETM } & \\ \mathrm{K} 1 & 607.76 & 666.09 & \mathrm{mWcm}^{\wedge} 2 \\ \mathrm{~K} 2 & 1260.56 & 1282.71 & \mathrm{~K}\end{array}$

$>\quad$ Step 4: calculate the NDVI

$$
\mathrm{NDVI}=(\mathrm{R} \text { band } 4-\mathrm{R} \text { band } 3) /(\mathrm{R} \text { band } 4-\mathrm{R} \text { band } 3)
$$

$\mathrm{R}$ band 4 and $\mathrm{R}$ band 3 are the land surface reflectance in the near infra-red and the visible bands respectively;

$>\quad$ Step 5: calculate Emissivity ( $(\varepsilon)$ from the NDVI

$$
\text { Emissivity }(\varepsilon)=1.0094+0.047 \mathrm{x} \text { In (NDVI) }
$$

$>\quad$ Step 6: compute the surface temperature (Ts)

$$
\text { Ts }=(\text { TEs }) /\{1+[\lambda \times(\text { TEs } / \rho)] \text { In } \varepsilon\}
$$

Where $\lambda$ is the wavelength of the emitted radiance $=11.5 \mu \mathrm{m}$ (Markham and Baker, 1985); and $\rho=\mathrm{hc} / \sigma=1.438$

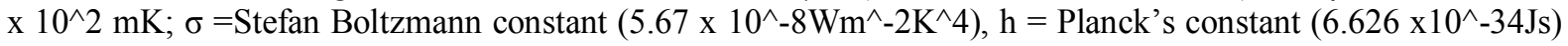
and $\mathrm{c}=2.998 \times 10^{\wedge} 8 \mathrm{~m} / \mathrm{s}$. 


\section{0: Introduction}

\section{Results And Discussion}

The objective of this study forms the basis of all the analysis carried out in this chapter. The results of this study are presented in form of maps, charts and statistical tables.

\section{1: Land use Land cover Distribution.}

The land use land cover distribution for the year of study (2002) is given in the Table below

Table 4.1: Land use Land Cover Distribution, 2002

\begin{tabular}{|c|l|c|c|c|}
\hline $\begin{array}{c}\text { LAND USE LAND } \\
\text { COVER/CATEGORIES }\end{array}$ & AREA (m) & AREA (\%) & NO OF PIXEL & \% OF PIXEL \\
\hline BARE SURFACE & 79097717.3 & 24.9 & 97381 & 24.90 \\
\hline BUILT UP & 70485430.5 & 22.1 & 86778 & 22.10 \\
\hline VEGETATION & 141337998.0 & 44.4 & 174,008 & 44.40 \\
\hline WATER BODY & 27372012.8 & 8.6 & 33699 & 8.60 \\
\hline TOTAL & $\mathbf{3 1 8 , 2 9 3 , 1 5 8 . 6}$ & $\mathbf{1 0 0}$ & $\mathbf{3 9 1 , 8 6 6}$ & $\mathbf{1 0 0}$ \\
\hline
\end{tabular}

The data of the Classified image (Table 4.1) shows that Vegetation occupies the largest area with $44.4 \%\left(141337998.0 \mathrm{~m}^{2}\right)$, followed by the bare surfaces which is about $25 \%\left(79097717.3 \mathrm{~m}^{2}\right)$ of the total area, built-up area and Water bodies occupies $22.1 \%\left(70485430.5 \mathrm{~m}^{2}\right)$ and $8.6 \%\left(27372012.8 \mathrm{~m}^{2}\right)$ respectively. The table also shows the number of pixels which is best described in the chart below.
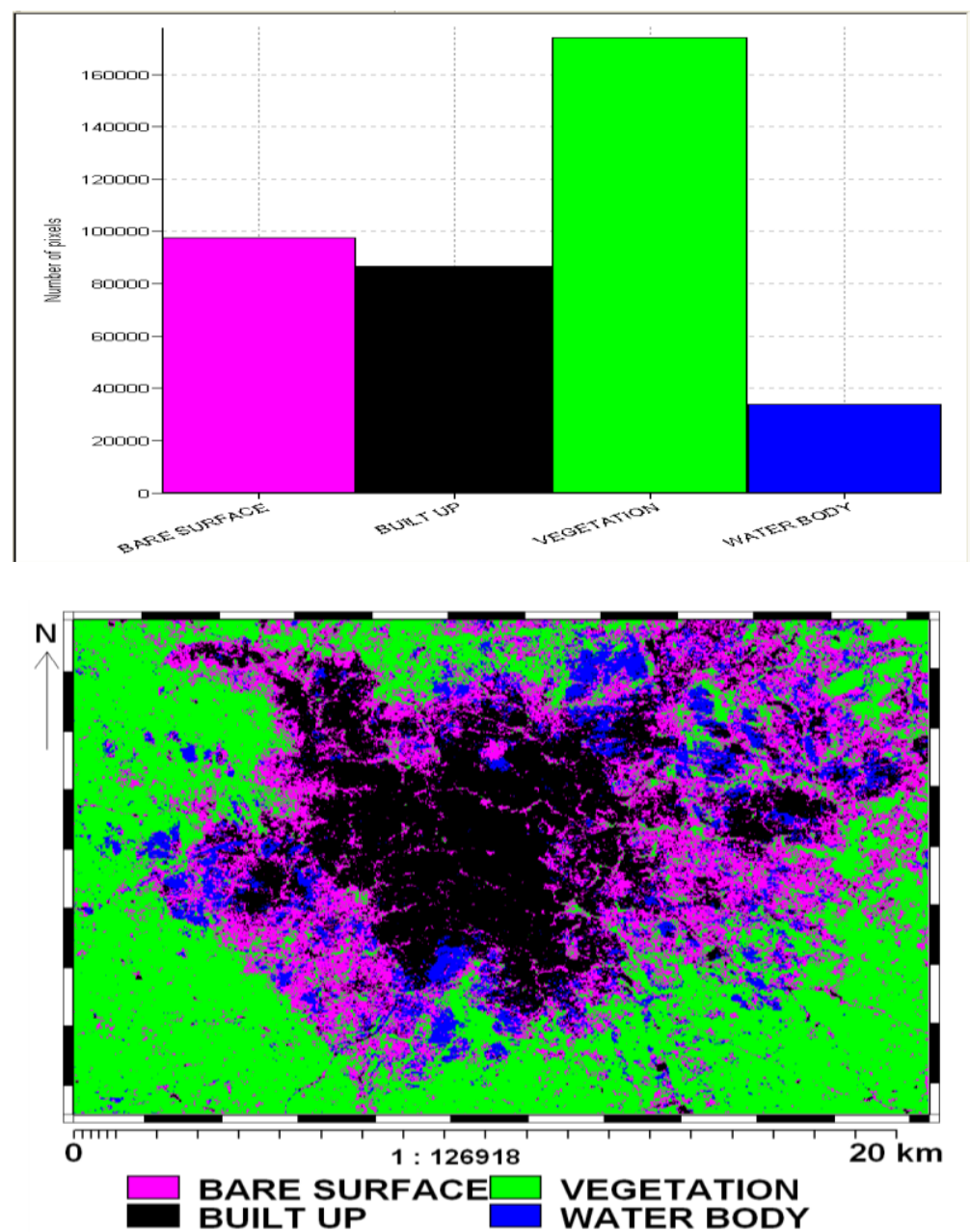


\section{2: Analysis of the spatial pattern of NDVI}

Spatial variation of NDVI is not only subject to the influence of vegetation amount, but also to topography, slope, solar radiation availability, and other factors (Walsh et al., 1997). NDVI is commonly used as a measure of land surface greenness based on the assumption that NDVI value is positively proportional to the amount of green vegetation in an image pixel area (Liu, 2009). This was verified in this study as fig.4.3 shows the variation of NDVI across Akure, the NDVI values for the vegetated areas were positive (though low) while the other classified features were negative. This low value of NDVI can be mainly attributed to the time of the year in which the images used (Landsat ETM+ bands 3 and 4) were taken. The images were acquired in the early part of the year, January to be precise when there is little or no rain to aid the greenness of the vegetation which in turn will increase the reflectance of the vegetated area. This shows that most of the vegetations across Akure are not photosynthentically active at that part of the year.

The other features namely, built-up, bare-surface, water bodies has negative NDVI values because they are not vegetated and the reflectance value in the red band is higher than reflectance value in Near Infra-red band.

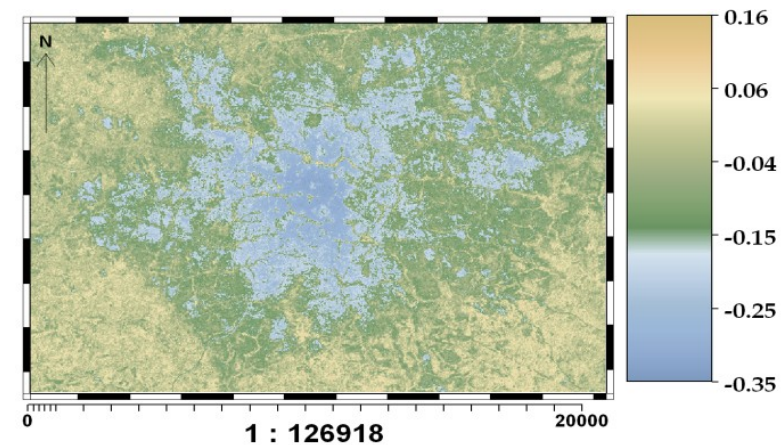

Fig.4.3: NDVI across Akure, 2002.

\section{3: Land Surface Temperature and Emissivity Distribution.}

To examine the spatial pattern of Surface Temperature in Akure, twenty transects were drawn across the city. This transects passes over various landscapes with different environmental settings, an inquiry into the Urban Heat Island characteristics of the profile will help to understand the factors shaping the city's thermal landscape. These factors include the spatial pattern of different land-cover classes, the occurrence of water bodies, parks, buildings and population densities and the division of the city's functional districts, among others (Weng, 2003).

The Thermal signatures of each land use land cover studied revealed the average values of surface temperature for each of these land use/cover type is shown in Table 4.2.

There was an obvious gradual thermal change from the urban area $\left(36^{\circ} \mathrm{C}\right)$ out into the suburban area $\left(26^{\circ} \mathrm{C}\right)$ as shown in figure 4.4. This implies that the urban area is majorly dominated by impervious surfaces such as concrete, metals and also asphalt on roads which are non-evaporating and non-transpiring. And also exhibits a high potential for absorption and radiation of heat alike with blackbodies, thereby having the highest temperature. The high rate of energy consumption, air-conditioning system, emission of plumes from industries and cars are also part of the factors responsible for the high surface temperature in the urban area.

Table 4.2: shows the derived Surface Emissivity and LST for different LULC

\begin{tabular}{|c|c|c|c|c|c|c|c|}
\hline \multirow[t]{2}{*}{ S/No } & \multirow{2}{*}{$\begin{array}{c}\text { LAND USE/LAND } \\
\text { COVER }\end{array}$} & \multicolumn{3}{|c|}{ SURFACE EMISSIVITY } & \multicolumn{3}{|c|}{ SURFACE TEMPERATURE $\left({ }^{\circ} \mathrm{C}\right)$} \\
\hline & & MIN & MAX & AVG & MIN & MAX & $\overline{\text { AVG }}$ \\
\hline 1 & BARE-SURFACE & 0.91 & 0.96 & 0.935 & 31 & 33 & 32 \\
\hline 2 & BUILT-UP & 0.90 & 0.95 & 0.925 & 33 & 36 & 34.5 \\
\hline 3 & VEGETATION & 0.97 & 0.98 & 0.975 & 26 & 29 & 27.5 \\
\hline 4 & WATER-BODY & 0.92 & 0.94 & 0.930 & 30 & 31 & 30.5 \\
\hline \multicolumn{7}{|c|}{ TOTAL SURFACE TEMPERATURE } & 124.5 \\
\hline & & & & \multicolumn{3}{|c|}{ AVERAGE SURFACE TEMPERATURE } & 31.1 \\
\hline
\end{tabular}




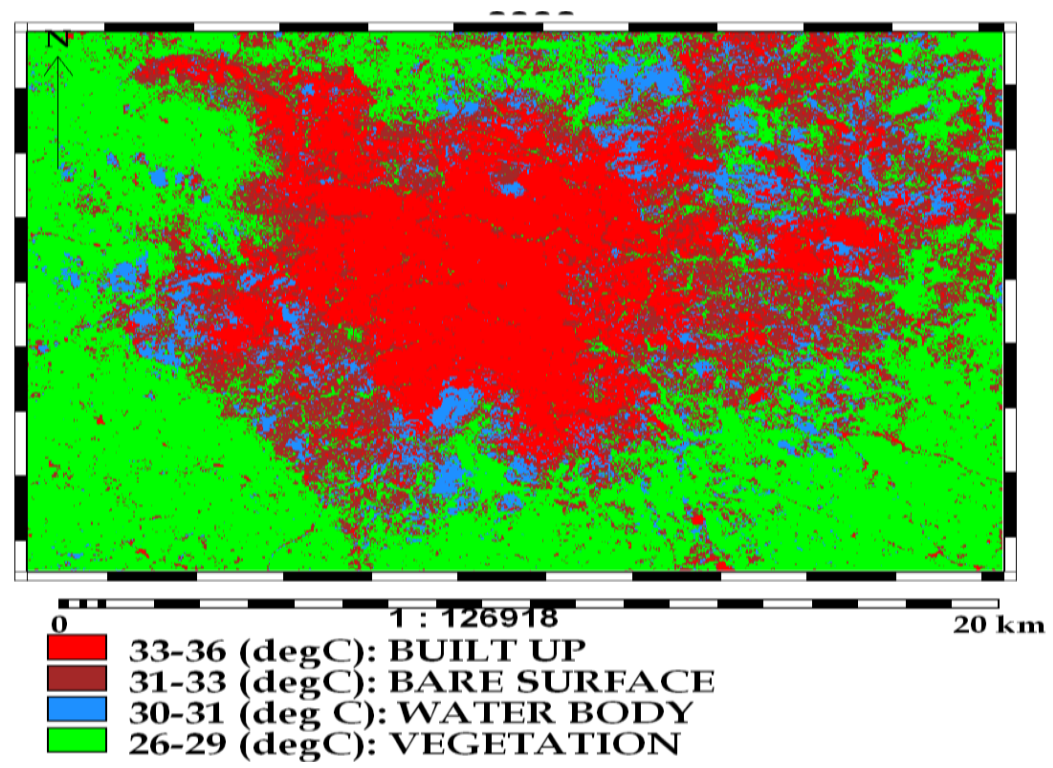

Fig.4.4: Surface Temperature range of different LULC in Akure, 2002.

Table 4.2 also shows the Land Surface Emissivity range for the classified different LULC over Akure, and fig. 4.5 shows the extent for the different features. The result shows that Vegetation over Akure has the highest emissivity values which range from $0.97-0.98$, closely followed by bare surfaces, water bodies, and built up areas with $0.91-0.96,0.92-0.94$ and $0.90-0.95$ respectively.

The high emissivity values recorded for Vegetations over Akure can be attributed to the fact that fully vegetated areas are approximate blackbodies. The emissivity spectrum is nearly constant and near unity.



Fig 4.5: Surface Emissivity range of different LULC in Akure, 2002.

\section{4: The spatial distribution of Land Surface Temperature}

The spatial distribution of land surface temperature is very important in urban climate studies. Figure 4.6 shows the spatial distribution of Land Surface Temperature over Akure and some hotspots of temperature were discovered. 


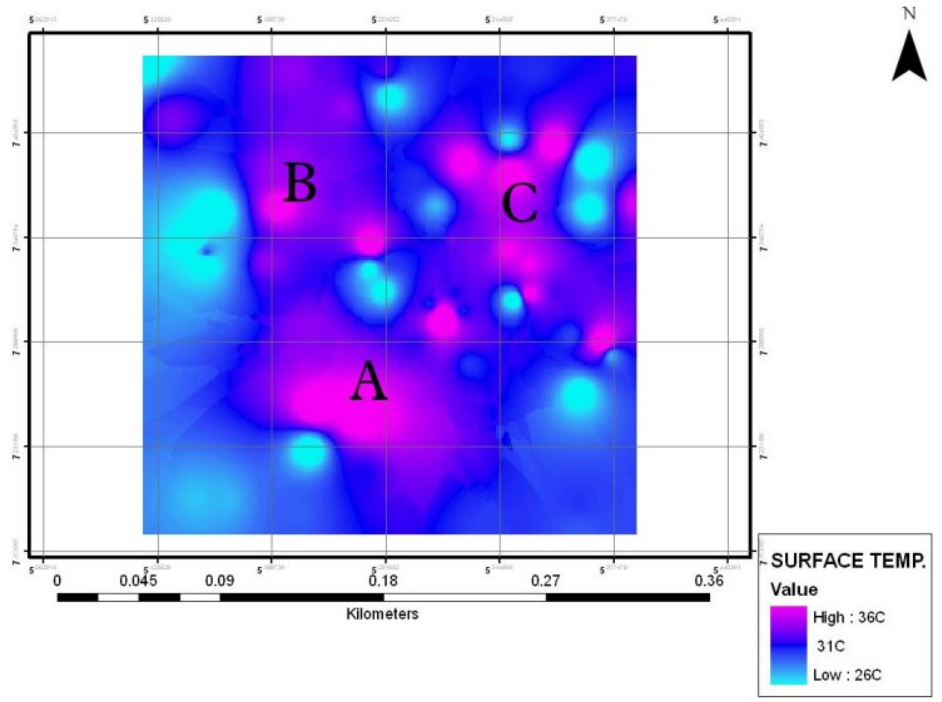

To confirm the factors responsible for this island of heat, the areas with high LST values were identified and it was discovered that areas like Alagbaka government area (A), Ondo road (B) and Igoba (C) have the highest LST values. The high temperature at Igoba can be traced to the fact that the area is actually a trough, surrounded by rock outcrop, also a lot of developmental activities are going on in the area. Ondo Road is also witnessing a lot of developmental activities which has modified the urban micro-climate of the area. The high LST values in $\mathrm{B}$ and $\mathrm{C}$ shows the expansion direction of the city.

The most extensive UHI was distributed in the central part of the Central Business District, comprising of the popular market (Oja-Oba), high court road and Alagbaka government area.

From the distribution of LST in Fig. 4.6, it can be found that the surface urban heat island is not always located in the center of the city, but sometimes in the outskirt. It was mainly because of the urban expansion and the new development sites were always in the outside of the city. The new developing sites destroyed the original ground land cover and enhance the land surface temperature.

\begin{tabular}{|c|c|c|c|c|c|c|}
\hline \multicolumn{7}{|c|}{ SUMMARY IN TABULAR FORM OF SPECTRAL RADIANCE, SAT. TEMPERATURE AND NDVI BY LOCATION. } \\
\hline Longitude & Latitude & Feature & DN & $\begin{array}{l}\text { Spectral } \\
\text { Radiance }(\mathrm{L} \lambda)\end{array}$ & Sat. $\operatorname{Temp}(\mathbf{K})$ & NDVI \\
\hline 5.118361 & 7.446111 & VEGETATION & 130 & 8.017644 & 298.2776476 & 0.5 \\
\hline 5.18675 & 7.332944 & B SFC & 134 & 8.1658792 & 299.4119684 & 0.2 \\
\hline 5.134028 & 7.411583 & WATER & 131 & 8.0547028 & 298.5621566 & 0.17 \\
\hline 5.251083 & 7.438889 & B SFC & 134 & 8.1658792 & 299.4119684 & 0.24 \\
\hline 5.294722 & 7.387611 & BUILT UP & 141 & 8.4252908 & 301.3737402 & 0.22 \\
\hline 5.199222 & 7.437917 & WATER & 133 & 8.1288204 & 299.1293126 & 0.19 \\
\hline 5.152889 & 7.333917 & VEGETATION & 130 & 8.017644 & 298.2776476 & 0.5 \\
\hline 5.254028 & 7.424583 & VEGETATION & 132 & 8.0917616 & 298.8460434 & 0.5 \\
\hline 5.228639 & 7.417917 & B SFC & 135 & 8.202938 & 299.6940151 & 0.22 \\
\hline 5.330778 & 7.315472 & BUILT UP & 139 & 8.3511732 & 300.8161957 & 0.19 \\
\hline 5.333389 & 7.439167 & WATER & 131 & 8.0547028 & 298.5621566 & 0.23 \\
\hline 5.289917 & 7.315972 & WATER & 134 & 8.1658792 & 299.4119684 & 0.27 \\
\hline 5.364083 & 7.362667 & VEGETATION & 132 & 8.0917616 & 298.8460434 & 0.5 \\
\hline 5.344583 & 7.397667 & BUILT UP & 142 & 8.4623496 & 301.6516401 & 0.2 \\
\hline 5.346528 & 7.316944 & B SFC & 137 & 8.2770556 & 300.2562983 & 0.31 \\
\hline 5.319639 & 7.400833 & VEGETATION & 131 & 8.0547028 & 298.5621566 & 0.4 \\
\hline 5.315944 & 7.423389 & B SFC & 136 & 8.2399968 & 299.975457 & 0.32 \\
\hline 5.321056 & 7.382139 & BUILT UP & 138 & 8.3141144 & 300.5365432 & 0.15 \\
\hline 5.303361 & 7.3415 & WATER & 132 & 8.0917616 & 298.8460434 & 0.19 \\
\hline 5.159139 & 7.360556 & VEGETATION & 130 & 8.017644 & 298.2776476 & 0.5 \\
\hline 5.212639 & 7.252278 & BUILT UP & 141 & 8.4252908 & 301.3737402 & 0.18 \\
\hline 5.153083 & 7.338111 & B SFC & 134 & 8.1658792 & 299.4119684 & 0.31 \\
\hline 5.254222 & 7.334417 & B SFC & 134 & 8.1658792 & 299.4119684 & 0.3 \\
\hline 5.190861 & 7.383139 & BUILT UP & 139 & 8.3511732 & 300.8161957 & 0.29 \\
\hline 5.243083 & 7.329111 & VEGETATION & 131 & 8.0547028 & 298.5621566 & 0.46 \\
\hline 5.283194 & 7.302611 & BUILT UP & 143 & 8.4994084 & 301.9289637 & 0.19 \\
\hline 5.268333 & 7.378722 & B SFC & 131 & 8.0547028 & 298.5621566 & 0.23 \\
\hline 5.294472 & 7.306333 & B SFC & 132 & 8.0917616 & 298.8460434 & 0.24 \\
\hline 5.319139 & 7.339389 & BUILT UP & 141 & 8.4252908 & 301.3737402 & 0.25 \\
\hline 5.36425 & 7.389 & VEGETATION & 132 & 8.0917616 & 298.8460434 & 0.64 \\
\hline
\end{tabular}


An Assessment Of Urban Heat Island In Akure Using Geospatial Techniques

\begin{tabular}{|l|l|l|l|l|l|l|}
\hline 5.371583 & 7.288417 & BUILT UP & 145 & 8.573526 & 302.4818976 & 0.21 \\
\hline 5.279083 & 7.363778 & VEGETATION & 134 & 8.1658792 & 299.4119684 & 0.43 \\
\hline 5.3895 & 7.365306 & B SFC & 131 & 8.0547028 & 298.5621566 \\
\hline 5.210111 & 7.229833 & VEGETATION & 130 & 8.017644 & 0.13 \\
\hline 5.192472 & 7.363472 & BUILT UP & 141 & 8.4252908 & 298.2776476 & 0.52 \\
\hline 5.244056 & 7.342 & BUILT UP & 139 & 8.3511732 & 301.3737402 & 0.21 \\
\hline 5.146361 & 7.344722 & VEGETATION & 131 & 8.0547028 & 298.5621566 & 0.13 \\
\hline
\end{tabular}

\subsection{Conclusion}

\section{Conclusion}

In this study, land surface temperatures were analyzed and it was found that the highest temperatures were not always in the center of the city, but also in the outskirt, especially the area with developing sites, taking Idanre Road and Igoba for example. The new built-up areas, because of fewer trees and green lands and more black asphalt concrete pavements, have higher surface temperature. Also the Central Business District (CBD) of Akure extending from the popular market (Oja-Oba) through Alagbaka government Area have the most significant Urban Heat Island (UHI) effect and this can be attributed to the high level of anthropogenic activities going on in the area, closely packed buildings with dark surfaces, roads with asphalts on it and other materials with very low albedo, rather than emitting, they absorb the greater part of the electromagnetic radiation that falls on them.

Also temperature comparison of the different land cover shows a great difference between them, Built up area has the highest temperature with $34.5^{\circ} \mathrm{C}$, closely followed by the bare surfaces with $32^{\circ} \mathrm{C}$, while Water bodies and Vegetations are $4^{\circ} \mathrm{C}$ and $7^{\circ} \mathrm{C}$ lesser than that of the built up area. These are all because different land cover has different albedo and thermal capacity

It has also been shown that satellite thermal data can indeed be used to characterize both the magnitude and spatial extent of an urban heat island. Through satellite remote sensing, an inquiry into thermal environment could be made.

\section{Reference}

[1]. Balogun A.A, Balogun I.A, Adefisan A.E, Abatan A.A (2009). Observed characteristics of the urban heat island during the harmattan and monsoon in Akure, Nigeria. Eight Conferences on the Urban Environment. AMS 89th Annual Meeting, $11-15$ January, 2009, Phoenix, AZ. Paper JP4.6.

[2]. Changnon, S.A. (1992), Inadvertent weather modification in urban areas: lessons for global climate change. Bulletin of the American Meteorological Society, Vol.73, Pp621-627.

[3]. Cohen, J.E. (1995), How many people can the Earth Support? W.W. Norton \& Co., New York.

[4]. Gallo, K.P., McNab, A.L., Karl, T.R., Brown, J.F., Hood, J.J. and Tarpley, J.D., 1993, the use of a vegetation index for asse ssment of the urban heat island effect. International Journal of Remote Sensing. 14: 2223-2230.

[5]. Ifatimehin, O. O. (2007).An Assessment of Urban Heat Island of Lokoja Town and Surroundings Using Landsat ETM data.

[6]. Ifeoluwa A. Balogun, Ahmed A. Balogun, and Zachariah D. Adeyewa (2009), A note on the effect of urbanization on air temperature and humidity of Akure, Nigeria.

[7]. Landsberg, H.E. (1981), the urban Climate. Academic Press, New York, Pp 6

[8]. Markham, B.L and Barker, J.K (1985) Spectral characteristics of the LANDSAT thematic Mapper sensors, International Journal of remote Sensing, Vol.6, pg. $697-716$

[9]. Nowak, D.J; Crane, D.E; Stevens, J.C and Ibarra, M. (2002), Brooklyn's Urban Forest.

[10]. Technical Report, US Department of Agriculture and forest service, pp 45

[11]. Oke, T.R. (1982), the energetic basis of the urban heat island. Quarterly Journal of the Royal Meteorological Society, Vol.108, Pp124.

[12]. Pickett, S.T.A; Cadenasso, M.L; Grove, J.M, Nilon, C.H.; Pouyat, R.V.Zipperer, W.C. and Costanza, R. (2001), Urban ecological systems: linking terrestrial ecological,

[13]. physical; and socioeconomic components of metropolitan areas. Annal review of Ecology and Systematics, Vol.32, Pp127-157

[14]. Pickett, S.T.A; Burch Jr, W.R; Dalton, S.E.; Foresman, T.W; Grove, J.M. and Rowntree, R. (1997), A conceptual framework for the study of human ecosystems in urban areas. Urban Ecosystems, Vol.1(4), Pp185-199

[15]. Rosa, E.A; York, R and Dietz, T. (2004), Tracking the Anthropogenic Drivers of Ecological impacts; Ambio- A Journal of the Human Enviroment, Vol. xxxiii (8), Pp 509-512

[16]. Sieferie, R.P. (2001), The Subterranean Forest: Ecology Systems and the Industrial Revolution. The White House Press, Cmabridge, U.K

[17]. Zhao, J and Wang, N. (2002), Remote Sensing analysis of urbanization effect on climate in Lanzhou. Arid Land Geography, Vol.25 (1), Pp. 90-95.

[18]. Zubair A.O. (2006), Change detection in land use and land cover using remote sensing data and GIS. 